\title{
Prevalence of antenatal risk conditions among women in an underserved district of Northern Sri Lanka
}

\author{
S Sivaganesh ${ }^{1}$ and $U$ Senarath ${ }^{2}$ \\ (Index words: antenatal risk conditions, antenatal morbidity, conflict, Sri Lanka)
}

\begin{abstract}
Objective To assess the prevalence of risk conditions among antenatal women in the Vavuniya District.

Design and setting A cross-sectional study was conducted among 392 pregnant women who had completed 36 weeks of gestation and were admitted or referred to two leading hospitals in the district.

Measurements Women were interviewed consecutively using a questionnaire, and their antenatal details were extracted from records by trained investigators. Data on socio-demographics, antenatal care utilisation, risk condition in present and past pregnancies, and preexisting illnesses were obtained.

Results Prevalence of an antenatal risk condition was $52.0 \%$. The common risk conditions included teenage $(9.7 \%)$ or elderly mother $(14.3 \%)$, anaemia $(8.2 \%)$ and abnormal BMI (8.2\%). The common risk conditions due to past pregnancy were: history of abortion (19.3\%), past caesarean delivery (8.0\%), and stillbirth/neonatal death $(4.8 \%)$. Less than half of the 'at risk' mothers were educated regarding the risk condition $(47.5 \%)$ or referred to $(48.5 \%)$ by the primary care providers. The majority was advised to deliver at a facility with emergency obstetric care.
\end{abstract}

Conclusions One in every two pregnancies in the Vavuniya District had an antenatal risk condition and services should be organised to meet this need.

\section{Introduction}

Improving maternal health is one of the millennium development goals to be achieved by the year 2015. Every year around half a million women in the world die from pregnancy-related causes and $99 \%$ of them are in the developing world [2]. Sri Lanka provides better maternal health services compared to many other developing countries, and probably reported the lowest maternal (38 per 100,000 live births) and infant mortality rates (11.2 per 1000 live births) in south Asia [4,5]. However, there are some underserved communities such as conflict-affected areas, estates and urban slums with poor maternal and child health indicators [6]. Antenatal care (ANC) utilisation in the Northern Province of Sri Lanka is poor as a consequence of the long-term armed conflict. The Vavuniya District has a large population of internally displaced persons (IDPs) for more than two decades, with a dramatic increase in numbers within the recent past. It was highlighted that the domiciliary care by public health midwives (PHM) and field antenatal clinic services were seriously affected due to shortage of staff in the district [7]. With this background investigation of antenatal risk conditions would be useful to deliver effective antenatal services in the area. The present study aimed to assess the prevalence of risk conditions among antenatal women and to describe the care provided by the primary health care providers in Vavuniya District.

\section{Methods}

We conducted a cross-sectional study from August to October 2007 on a sample of 392 pregnant women who had completed 36 weeks of gestation, and were either referred to or admitted for delivery to the General Hospital Vavuniya (GHV) and the District Hospital Cheddikulam (DHC) in the Vavuniya District. These two hospitals served almost $98 \%$ of the total deliveries of the district according to district health statistics in 2006 [8]. The sample size was calculated using the standard formula for a prevalence estimate with the main outcome measure (prevalence of any risk condition) $48 \%$, alpha error 0.05 , and the level of precision 5\%. Trained interviewers collected data using an interviewer administered questionnaire and obtained information on socio-demographic characteristics, household details, community characteristics and ANC utilisation. Data on antenatal risk conditions were extracted from the pregnancy records. The Ethics Review Committee of the Faculty of Medicine of the University of Kelaniya, Sri Lanka granted approval for the study. The investigators obtained informed verbal consent from each selected participant before the interview.

\section{Results}

\section{Socio-demographic characteristics}

The majority were Sri Lankan Tamils by ethnicity (82.4\%), and Hindus by religion (71.2\%) (Table1). More than half (54\%) of the mothers had completed the GCE (O/L) examination. Approximately $66 \%$ of antenatal mothers lived in their own house, $8 \%$ in refugee or resettled

${ }^{1}$ Office of the Divisional Director of Health Services, Vavuniya, Sri Lanka and ${ }^{2}$ Department of Community Medicine, Faculty of Medicine, University of Colombo, Sri Lanka.

Correspondence: SS, e-mail <sivape@yahoo.com>. Received 16 April and revised version accepted 30 July 2009. Competing interests: none declared. 
camps and $26 \%$ in other places such as relation's or rented property. Nearly $71 \%$ of the mothers lived within $6 \mathrm{~km}$ from a health facility. More than half of the respondents (58.4\%) reported that their family was affected directly by the conflict and almost all the affected had been displaced at some time.

\section{Antenatal care utilisation}

Approximately $68.4 \%$ of mothers were registered by PHM for ANC, 31.4\% registered before 12 weeks of gestation and $38.5 \%$ were visited at home by PHM. Ninety percent of mothers made at least four antenatal clinic visits.

Table 1. Socio-demographic characteristics of antenatal mothers

\begin{tabular}{|c|c|c|}
\hline Characteristic & No. & $\%$ \\
\hline \multicolumn{3}{|l|}{ Ethnicity } \\
\hline Sri Lankan Tamil & 323 & 82.4 \\
\hline Sinhalese & 25 & 6.4 \\
\hline Moor & 39 & 9.9 \\
\hline Indian Tamil & 5 & 1.3 \\
\hline \multicolumn{3}{|l|}{ Religion } \\
\hline Hindu & 279 & 71.2 \\
\hline Buddhist & 25 & 6.4 \\
\hline Islam & 39 & 9.9 \\
\hline Christian & 49 & 12.5 \\
\hline \multicolumn{3}{|l|}{ Education level of mother } \\
\hline No schooling & 09 & 2.3 \\
\hline Grade 1-5 & 37 & 9.4 \\
\hline Grade 6-10 & 135 & 34.4 \\
\hline G.C.E. ordinary level & 119 & 30.4 \\
\hline G.C.E. advanced level and above & 92 & 23.5 \\
\hline \multicolumn{3}{|l|}{ Type of residence } \\
\hline Own house & 260 & 66.3 \\
\hline Resettled camp & 31 & 7.9 \\
\hline Other place & 101 & 25.8 \\
\hline \multicolumn{3}{|l|}{ Residential sector } \\
\hline Rural & 225 & 57.4 \\
\hline Urban & 167 & 42.6 \\
\hline \multicolumn{3}{|l|}{ Distance to health facility } \\
\hline Less than $6 \mathrm{~km}$ & 276 & 70.5 \\
\hline $6 \mathrm{~km}$ and above & 116 & 29.5 \\
\hline \multicolumn{3}{|l|}{ Family affected directly by conflict } \\
\hline Yes & 229 & 58.4 \\
\hline \multirow[t]{2}{*}{ No } & 163 & 41.6 \\
\hline & Total & 100.0 \\
\hline
\end{tabular}


Table 2. Prevalence of risk conditions in the present or past pregnancy among antenatal women $(n=392)$

\begin{tabular}{|c|c|c|}
\hline Risk condition & No. & $\%$ \\
\hline \multicolumn{3}{|l|}{ Risk conditions in the present pregnancy } \\
\hline Age $<19$ years & 38 & 9.7 \\
\hline Age $\geq 35$ years & 56 & 14.3 \\
\hline Primiparae & 143 & 36.4 \\
\hline Grand multiparae (5th or higher parae) & 39 & 9.9 \\
\hline Anaemia & 32 & 8.2 \\
\hline $\mathrm{BMI}<18.5$ & 22 & 5.6 \\
\hline $\mathrm{BMI} \geq 25$ & 10 & 2.6 \\
\hline Weight $<38 \mathrm{~kg}$ & 5 & 1.3 \\
\hline Height $<135 \mathrm{~cm}$ & 6 & 1.5 \\
\hline Rh negative & 9 & 2.3 \\
\hline Hypertension/Pregnancy induced hypertension & 5 & 1.3 \\
\hline Diabetes complicating pregnancy & 6 & 1.5 \\
\hline Heart disease & 4 & 1.0 \\
\hline Abnormal presentation or lie & 4 & 1.0 \\
\hline Per vaginal bleeding & 1 & 0.3 \\
\hline Multiple pregnancy & 2 & 0.5 \\
\hline Placenta praevia & 1 & 0.3 \\
\hline Bronchial asthma & 3 & 0.8 \\
\hline Chickenpox & 2 & 0.5 \\
\hline Unknown period of amenorrhoea & 3 & 0.8 \\
\hline \multicolumn{3}{|l|}{ Risk conditions related to previous pregnancies ${ }^{\mathrm{a}}$} \\
\hline Abortion & 48 & 19.3 \\
\hline Caesarean delivery & 20 & 8.0 \\
\hline Still birth & 9 & 3.6 \\
\hline Neonatal death & 3 & 1.2 \\
\hline Hypertension in pregnancy & 6 & 2.4 \\
\hline Haemorrhage (antepartum /postpartum) & 2 & 0.8 \\
\hline Ectopic pregnancy & 1 & 0.4 \\
\hline
\end{tabular}

${ }^{\mathrm{a}} 143$ primi mothers were excluded

Table 3. General measures taken by the primary healthcare providers for antenatal women with risk conditions $(n=204)$

\begin{tabular}{lrc}
\hline Measure or intervention & No. & $\%$ \\
\hline Red sticker or ink in the pregnancy record & 132 & 65.2 \\
Education of mother about complications & 97 & 47.5 \\
Education of family about complications & 27 & 13.3 \\
Referral by primary healthcare provider & 99 & 48.5 \\
Follow up at home after the referral & 29 & 14.2 \\
Advice on delivery at emergency obstetric care facility & 180 & 88.2 \\
\hline
\end{tabular}




\section{Antenatal risk conditions and general measures}

Approximately 52\% $(n=204)$ of mothers had at least one risk condition related to either the past or present pregnancy, and this percentage was exclusive of primiparae which constituted $36.5 \%$ of the sample. It is important to note that a considerable proportion reported more than one risk condition. Table 2 illustrates the prevalence of risk conditions in present or previous pregnancies.

Prevalence of any risk condition in the present pregnancy includes teenage $(9.7 \%)$ or elderly mother (14.3\%), grand multi parity (9.9\%), anaemia in pregnancy (8.2\%), low or high BMI (5.6 and 2.6\% respectively) and Rh negative mother (2.3\%). Prevalence of medical conditions complicating pregnancy such as hypertension, diabetes and heart disease were relatively low in the sample. Among the 249 (65.5\%) mothers who had a previous pregnancy, leading risk conditions due to past pregnancy were, history of abortion (19.3\%), past caesarean delivery (8.0\%), and still birth/neonatal death (4.8\%). Only few past pregnancies were complicated with antepartum or postpartum haemorrhage.

Table 3 describes some general measures taken by the primary healthcare providers for the 204 mothers at risk. Of the mothers only two-thirds had their pregnancy records labelled with red sticker or ink. Less than half of the 'at risk' mothers were educated regarding the possible complications. Nearly half (48.5\%) of 'at risk' mothers were referred by a primary healthcare provider for further assessment or management and $14.2 \%$ were followed up after referral by these care providers. Majority of the 'at risk' mothers (88.2\%) were advised to seek delivery services from a centre with emergency obstetric care services. The health education or home visits or clinic care provided to mothers with identified risks were almost similar to mothers without risk.

\section{Discussion}

The Vavuniya District has a large IDP population for more than two decades. Approximately 8\% of mothers in our study population lived in refugee or resettled villages mainly at Poonthoddam and few other places. These resettled villages are different from the present IDP camps and the people have been living there for more than 10 years.

The number of antenatal clinic visits made by women in the present study was comparable to the national situation [4]. Our results regarding the antenatal clinic attendance were consistent with the findings of two previous studies conducted in conflict affected areas Mallavi and Kopay - within the Northern Province [9, 10]. Increased attendance to antenatal clinics despite the conflict situation is a favourable indication for ANC utilisation, thus service providers should focus more on quality of care, rather than increasing the frequency of routine visits.
According to our findings one in two mothers had an antenatal risk condition. The rate of teenage pregnancies was higher in our study (9.7\%) than the national data (6.2\%) available in the Reproductive Health Management Information System (RHMIS) of the Family Health Bureau [4]. The proportion of mothers with a previous history of abortion was higher than the reported rate at national level. Prevalence of both thinness and obesity were low in the study area compared to the national rates - among the pregnant women studied 5.6\% had BMI less than $18.5 \mathrm{~kg} / \mathrm{m}^{2}$ and $2.6 \%$ had BMI higher than $25 \mathrm{~kg} / \mathrm{m}^{2}$ in contrast to $26.6 \%$ and $12.0 \%$ respectively in the national data. In our study, $8 \%$ of non-primi mothers had undergone caesarean deliveries in contrast to $23.8 \%$ as revealed by the Demographic and Health Survey conducted during the same period [11]. Prevalence of anaemia in pregnancy was $8.2 \%$ in our study which was markedly lower than the national figure of $30.3 \%$ found in a study conducted by the Medical Research Institute [12]. This comparison should be made with due caution because our findings were based on haemoglobin values documented in pregnancy records through different sources. The spectrum of ANC risk conditions identified by our study showed a similar pattern with the results of a study conducted in an underprivileged community with a similar background in the Mullaitivu district [9].

Another important finding is the high abortion rate and it is necessary to further investigate the underlying factors and consequence of such abortions. Abortions, either spontaneous or induced, remain a significant cause of maternal morbidity and mortality in the developing world [2], necessitating action to address this problem.

The general measures taken by primary care providers on 'at risk' pregnancies were insufficient except the advice requesting delivery at a centre with emergency obstetric care. A study done in USA had concluded that lack of prenatal care should be considered as a high-risk factor for post-neonatal death for both African-American and white women, especially if the pregnancy has been complicated by postdates, pregnancy-induced hypertension, intra partum fever or small-for-gestational-age infant [13]. Hence 'at risk' mothers should be specially targeted by healthcare providers in health education activities. However, our study showed that health education or home visits or clinic care provided to mothers with identified risks were almost similar to mothers without risk.

Our study had some limitations. As this study was conducted at two large hospitals mothers who sought services at smaller hospitals or delivered at home were not included. Some of the information was subjected to recall bias. The prevalence of medical conditions was entirely based on pregnancy record or mothers' statement and this is possibly an underestimate of the actual situation. 


\section{Conclusion}

The overall rates of risk-related pregnancies or antenatal morbidities were high in the Vavuniya District and the health care services have not met the actual need. It is necessary to plan and implement health services in the district focusing on the leading antenatal issues.

\section{References}

1. United Nations. United Nations Millennium Declaration Network - New York: United Nations, 2000.

2. World Health Organization, Unsafe abortion: Global and regional estimates of the incidence of unsafe abortion and associated mortality in 2000, 4th edition. Geneva: World Health Organization, 2004.

3. Wright DJ. A brief history of midwifery. Available from: $<$ www.shef.ac.uk/ nmhuk/midwife/timline/ midtimeline.html> [Accessed 22 October, 2007].

4. Ministry of Healthcare and Nutrition. Annual Report on Family Health Sri Lanka 2004-2005. Colombo: Ministry of Health, 2007.

5. Department of Census and Statistics. Infant mortality per 1000 live births by district, 1991-2003. Statistical Abstract 2007. Colombo: Department of Census and Statistics, 2007.

6. De Silva JKM, Wickramasuriya KP. Maternal and child health and family planning services in Sri Lanka. The Journal of the College of Community Physicians of Sri Lanka 2001: 12-20.

7. Sivaganesh S, Senarath U. Antenatal care utilisation in a conflict-affected district of Northern Sri Lanka. Public Health Nursing, 2009 (in press).

8. Deputy Provincial Director of Health Services. Statistical Hand Book 2005. Vavuniya: Office of the DPDHS Vavuniya, 2006.

9. O Reilley BS, Joseph M, et al. Obstetrics during civil war: six months in maternity ward in Mallavi, Northern Sri Lanka. Medicine Conflict and Survival 2002; 18: 258-70.

10. Surenthirakumaran, R. Maternal and child health services in Kopay MOH area (Jaffna district) and factors associated with provision of services. Dissertation (MSc). Colombo: University of Colombo, 2007.

11. Department of Census and Statistics Sri Lanka. Sri Lanka Demographic and Health Survey 2006-07. Colombo: Department of Census and Statistics, 2009.

12. Medical Research Institute. Assessment of anaemic status in Sri Lanka - 2001. A survey report. Colombo: Ministry of Health, 2003.

13. Vintzileos A, Ananth CV, Smulian JC, Scorza WE, Knuppel RA. The impact of prenatal care on postneonatal deaths in the presence and absence of antenatal high-risk conditions. American Journal of Obstetrics and Gynecology 2002; 187: 1258-62. 